\title{
Reasons for Forming Particulate Matter in Exhaust Gases of Internal Combustion Engines

\author{
${ }^{1}$ Larisa M. Gabsalikhova, ${ }^{2}$ Irina V. Makarova, ${ }^{3}$ Eduard M. Mukhametdinov, ${ }^{4}$ Polina A. Buyvol, ${ }^{5}$ Aleksandr S. \\ Barinov \\ ${ }^{1-4}$ Kazan Federal University \\ ${ }^{5}$ Murmansk State Technical University \\ Email: muhametdinoval@mail.ru
}

\author{
Received: 23 ${ }^{\text {rd }}$ July 2019, Accepted: 10 $^{\text {th }}$ August 2019, Published: $3^{\text {st }}$ August 2019
}

\begin{abstract}
Measuring the amount of particles in the exhaust gas plays an important role in the automotive sector, it begins more important with the introduction of Euro standards which limit the amount of harmful substances entered the air together with the exhaust gases of an automobile engine. Exhaust gas contact is associated with adverse health effects on the respiratory system, cardiovascular system, and increased morbidity and mortality. They are a heterogeneous mixture of various gaseous substances with various chemical and physical properties, consisting of products of complete and incomplete combustion of fuel, excess air, aerosols and various trace elements. The main standardized toxic components of diesel engine exhaust gases are carbon, nitrogen and hydrocarbon oxides, carbon black.

The article discusses the process of formation of particulate matter in the exhaust gases of internal combustion engines. An analysis of the reasons of particulate matter in exhaust gases is made. By analyzing the exhaust gases and testing the degree of deviation of actual combustion results from the desired, various problems can be resolved. Throughout the right approach to the analysis of the composition of the exhaust gases, a conclusion about the efficiency of the internal combustion engine can be made.
\end{abstract}

\section{Keywords}

Particulate Matter, Carbon Black, Exhaust Emissions, Diesel Engine.

\section{Introduction}

One of the priority directions for the formation of the sustainable development of the social and economic system of Russian Federation, contributing to the transition to "green" growth, reducing the load on the environment, increasing the efficiency of natural resource use, is the implementation of the concept of transition to a low-carbon economy. The key elements of this economy are more economical and environmentally friendly transport. Road transport is one of the main polluters of the environment, primarily atmospheric air. The exhaust gases of automotive engines contain over 300 components, including highly toxic substances.

In Russia, the Euro-5 standard is in place. It limits the amount of harmful substances that enter the air together with the exhaust gases of an automotive engine. Admissible standards of carbon black are $0.005 \mathrm{~g} / \mathrm{km}$ (direct injection). Studies confirm the association of morbidities associated with the cardiovascular system, and increased mortality from carbon black exposure. A black cloud indicates carbon black in the engine exhaust, while the transparency of the exhaust changes (the optical density increases).

Researching the quality of the fuel combustion process in engines can help in the development of measures to improve their efficiency, which in turn will reduce the negative load on the environment.

\section{Methods}

Air pollution is considered hazardous to human health. Many researches have noted the role of particulate matter in air as an active environmental pollutant [1,2]. Exposure to particulate matter is associated with adverse health effects of the respiratory and cardiovascular systems [3], as well as an increase in morbidity and mortality rates [2]. This is evidenced by numerous epidemiological researches of the connection between exposure to particulate matter and the occurrence of acute respiratory infections, cardiovascular and chronic respiratory morbidities, lung cancer [4,5]. Measurements of human respiration before starting and turning off the vehicle were used to assess the impact of automotive exhaust emissions on human health [6].

The connections between the chemical composition and toxicity of particles tend to be stronger for small and ultrafine fractions [1]. The issues of the distribution of particulate matter by fractions during the combustion of diesel fuel were also considered in $[7,8]$.

Emissions from a diesel engine depend on the nature of the interaction of fuel and air in the engine cylinder. High temperatures that contribute to the oxidation of carbon black also contribute to the formation of nitrogen oxide. Control over these interactions can lead to cleaner combustion, lower engine emissions [9]. The article [10] shows the effect on the properties of particles in the exhaust gases of devices for their subsequent processing, such as particle traps and catalytic converters. 
Road and laboratory assessment of exhaust emissions was analyzed in articles [11, 12, 13]. Thus, the authors of [12] established that sulfuric acid and water are the nucleating agent of carbon black. It was found that nucleation of particles even at high engine loads can be suppressed by using low sulfur fuels.

The connection between emissions from road transport and the destruction of decorative limestone using sulfation processes is shown in [14]. Tandem differential mobility analyzers were used to measure particles emitted by a diesel engine. The application of standards to control emissions of diesel engines has led to a significant reduction in the mass of emitted particles. Some low-emission diesel engines emit much higher concentrations of nanoparticles than older low-emission designs. Researches show that at the same mass concentrations, nanometer-sized particles are more dangerous than micron-sized particles [15].

Carbon black exacerbates wear at engine contact points where lubrication is least likely. The most likely place where wear occurs is the valve mechanism, since it is located in the upper part of the engine and is not lubricated enough, especially during cold starts, due to the fact that low oil pressure and high oil viscosity are typical for the engine idle.

\section{Results and Discussion}

Particulate matter in the exhaust gases are quite various. Their characteristics depend on the fuel and oil used, and process parameters. The requirements for the operation of diesel engines and their reliability set the task of measuring both the concentration of carbon black and its dispersion. In order that carbon black does not form during the combustion of diesel fuel, it is necessary to ensure certain conditions. Carbon black is formed in the combustion zones of poor mixtures, as well as inside the fuel stream, due to over-enrichment with fuel.

When analyzing the process of formation of particulate matter, as a rule, a certain scheme is used. It consists of the processes of hydrogenation, dehydrogenation, cracking, polymerization and condensation of chemical components. In this model, the process of carbon black formation during combustion of hydrocarbon fuels is conditionally divided into three main periods: nucleation; germ growth in carbon black; coagulation of primary carbon black.

For complete combustion, the correct ratio of oxygen to carbon black particles is necessary. In this case, the particle size must be determined in order to ensure normal combustion. With a lack of oxygen molecules, compounds of particulate matter occur in carbon black. The density of carbon black compounds depends on the qualitative composition of the elements from which they are formed.

To measure the concentration of carbon black particles, thermogravimetric and infrared analysis, a deposition method, paper chromatography, photon correlation spectroscopy, and electrical methods are used.

The content of substances in the exhaust gases of internal combustion engines is shown in table 1

\begin{tabular}{|l|l|l|}
\hline Component & Gasoline engine, & Diesel engine \\
\hline Nitrogen & $74 \ldots 77$ & $74 \ldots 78$ \\
\hline Oxygen & $0,3 \ldots 10,0$ & $2 \ldots 18$ \\
\hline Water vapor & $3,0 \ldots 5,5$ & $0,5 \ldots 9,0$ \\
\hline Carbon Dioxide & $5 \ldots 12$ & $1 \ldots 12$ \\
\hline Carbon monoxide & $0,5 \ldots 12,0$ & $0,005 \ldots 0,4$ \\
\hline Nitrogen oxide & $0,01 \ldots 0,80$ & $0,004 \ldots 0,5$ \\
\hline Hydrocarbons & $0,2 \ldots 3,0$ & $0,009 \ldots 0,3$ \\
\hline Alidyegids & till 0,2 & $0,001 \ldots 0,009$ \\
\hline Carbon black, $\mathrm{g} / \mathrm{m}^{3}$ & till 0,004 & $0,01 \ldots 1,1$ \\
\hline Benzo(a)pyrene, $\mathrm{mcg}^{3} \mathrm{~m}^{3}$ & till 25 & till 10 \\
\hline Sulfur oxide & till 0,008 & $0,002 \ldots 0,02$ \\
\hline Lead oxide & till 0,02 & Absent \\
\hline
\end{tabular}

\section{Table 1: The Content of Substances in the Exhaust Gases of Internal Combustion Engines, \% by Volume}

The table shows that the carbon black content in the exhaust gases of diesel internal combustion engines is quite large. A carbon black particle is an agglomerate of crystallites, which, in turn, consist of a set of separate networks (plates) of graphite hexagons. In addition to carbon, carbon black contains 1-3\% by weight (i.e. 10-30\% by number of atoms) of hydrogen, which can be chemically or physically bonded to carbon.

Carbon black formation is a volumetric process of thermal decomposition (pyrolysis) of hydrocarbons in the gas (vapor) phase under conditions of a severe deficiency (absence) of an oxidizing agent (oxygen).

The hydrocarbon pyrolysis reaction can be expressed by the equation

$C_{m} H_{m} \leftrightarrow n C+0,5 m H_{2}$

The most general scheme includes hydrogenation, dehydrogenation, cracking (i.e., molecular cleavage), polymerization, condensation (i.e., the union of molecules causing the formation of very large molecules of a different type).

The speed of carbon black formation depends on the speed of chemical processes that entail the emergence of the nucleus (i.e., the kinetics of the process). 
At temperatures below $1500 \mathrm{~K}$ (low temperatures), polymerization and condensation reactions predominate and, in most cases, nucleus of aromatic or polycyclic compounds form. At temperatures from 2000 to $3500 \mathrm{~K}$, the molecules decompose and break down.

It should be noted that the formation of carbon black in a pre-mixed and diffusion flame (laminar and turbulent) also occurs through the pyrolysis of hydrocarbon molecules.

The amount of carbon black formed largely depends on the temperature in the zone of hydrocarbon pyrolysis. With increasing temperature, this amount increases rapidly, since the reaction rate (1) is controlled by its kinetics. The increase in pressure is similarly affected.

It is established that the formation of carbon black depends on the properties of the fuel. The higher the molecular weight of straight-chain saturated and unsaturated hydrocarbons, the higher the rate of carbon black particle formation. This fact is explained that the strength of the same bond depends on the length of the molecule. So, with an increase in the number of carbon atoms in the molecule from 2 to 5 , the bond strength between the $\mathrm{CH}$ groups of alkanes decreases from 333 to $268 \mathrm{~kJ} /$ mol. It is revealed also that it is more concentration of soot of subjects, than the carbon relation to hydrogen $(\mathrm{C} / \mathrm{H})$ in fuel is higher.

Different hydrocarbons (with the same number of $\mathrm{C}$ atoms) in terms of increasing propensity to form carbon black are located as follows: normal paraffins, isoparaffins, cycloparaffins, olefins, cycloolsphn, deolefins, aromatics.

In diesel engines, a phenomenon can be observed when, under heavy load, fuel containing aromatic hydrocarbons produces less smoke than fuel containing paraffins. This is due to a longer induction period in the case of fuel combustion with aromatic hydrocarbons, as a result of which the mixture in the combustion chamber has more chances to become homogeneous before combustion begins.

In the process of formation and after the formation of carbon black particles, they can burn out in reactions with $\mathrm{OH}$ radicals or oxygen. Basically, when the composition of the mixture is poorer than the stoichiometric (in diesel engines), direct carbon black oxidation with oxygen occurs. The rate of carbon black burning is much lower than the rate of burning of gaseous products of incomplete combustion (for example, $\mathrm{CO}$ ). The rate of carbon black burnout substantially depends on the particle size (surface).

In the diesel cylinder diffusion combustion of a heterogeneous mixture occurs. Moreover, in the flame zone itself, the composition of the mixture is close to stoichiometric, and temperatures are correspondingly high. These hightemperature zones adjoin zones with a significantly richer mixture; here favorable conditions are created for pyrolysis with very low oxygen access. Thus, the nature of mixture formation and combustion in diesel engines predetermines much more carbon black formation compared to spark ignition engines.

The primary structures that make up the carbon black formed in diesel engines are spherical particles with a diameter of 150 - 1700 A with a specific surface area of up to $76 \mathrm{~m} 2 / \mathrm{g}$. However, even in the process of combustion, coagulation of carbon black particles occurs, leading to the formation of secondary and tertiary structures. Carbon black in the exhaust gases of diesel engines is an irregularly shaped formation with linear dimensions of 0.3-100 microns. Most of the carbon black formations are 0.4-5 microns in size. In the process of gas expansion in the cylinder of a diesel engine, oxygen enters the carbon black particles (due to the movement of gases and oxygen diffusion), that is, conditions favorable for soot burning are created [16].

Therefore, the emission of carbon black from the exhaust gases of a diesel engine depends both on the formation process and on the process of its combustion. Carbon black formation in diesel engines can also occur when fuel streams hit the relatively cold cylinder walls.

\section{Summary}

Modern requirements for the operation of diesel engines and their reliability set the task of measuring both the concentration of carbon black and its dispersion. For complete combustion, the correct ratio of oxygen to carbon black particles is necessary. In this case, the particle size must be determined in order to ensure normal combustion. With a lack of oxygen molecules, compounds of particulate matter occur in carbon black. The speed of carbon black formation depends on the speed of chemical processes that entail the emergence of the nucleus.

\section{Conclusions}

As a result, it is possible to say that throughout the right approach to the analysis of exhaust gases, the overall performance of the internal combustion engine can be estimated. Based on these conclusions, it is possible to adjust the operation of the engine, which will increase its efficiency and environmental friendliness. Researching the process of formation of particulate matter in the exhaust gases will make it possible to carry out measures to modernize engines and mechanisms responsible for mixture formation in the combustion chamber, which will contribute to more efficient operation of engines. And then, a more efficient usage of fuel in the operation of internal combustion engines will reduce transport costs.

\section{Acknowledgements}

The work is performed according to the Russian Government Program of Competitive Growth of Kazan Federal University. 


\section{References}

[1] A. Valavanidis, "Airborne Particulate Matter and Human Health: Toxicological Assessment and Importance of Size and Composition of Particles for Oxidative Damage and Carcinogenic Mechanisms", Journal of Environmental Science and Health, Part C Environmental Carcinogenesis and Ecotoxicology Reviews, vol. 26, issue 4., p.p.339-362, 2008.

[2] A. Valavanidis, K. Fiotakis, E. Bakeas, T. Vlahogianni, "Electron paramagnetic resonance study of the generation of reactive oxygen species catalysed by transition metals and quinoid redox cycling by inhalable ambient particulate matter. Redox Report”, Communications in Free Radical Research, vol. 10, issue 1, p.p. 37-51, 2005.

[3] J. F. Argacha, T. Bourdrel, P. van de Borne, "Ecology of the cardiovascular system: A focus on air-related environmental factors ", Trends in Cardiovascular Medicine, vol. 28, Issue 2, p.p.112-126, 2018.

[4] Theo M.C.M.de Kok, Hermen A.L.Driece, Janneke G.F.Hogervorst, Jacob J.Briedé, "Toxicological assessment of ambient and traffic-related particulate matter: A review of recent studies", Mutation Research/Reviews in Mutation Research, vol. 613, Issues 2-3, p.p. 103-122, 2006.

[5] L. Risom, P. Møller, S. Loft, "Oxidative stress-induced DNA damage by particulate air pollution”, Mutation Research. Fundamental and Molecular Mechanisms of Mutagenesis, vol. 592, Issues 1-2, p.p. 119-137, 2005.

[6] M.Kacema, K.Zaghdoudi, A.Morales-Rubio, M.de la Guardia, "Preliminary results on the influence of car characteristics on their gases emissions using gas sensors", Microchemical Journal ,vol. 139, p.p. 69-73, 2018.

[7] Stephen J. Harris, M. Matti Maricq, "Signature size distributions for diesel and gasoline engine exhaust particulate matter", Journal of Aerosol Science, vol. 32, issue 6, p.p. 749-764, 2001.

[8] J. Cisek, "The influence of RME on mass and number concentration of nano PM in exhaust gases from a diesel engine”, Journal of KONES, vol. 21, No. 2, p.p. 53-60, 2014.

[9] F. Leach, R. Ismail, M. Davy, "Engine-out emissions from a modern high speed diesel engine - The importance of Nozzle Tip Protrusion", Applied Energy, vol. 226, 15, p.p. 340-352, 2018.

[10] H.Burtscher ,"Physical characterization of particulate emissions from diesel engines: a review", Journal of Aerosol Science, vol. 36, issue 7, p.p. 896-932., 2005. DOI: 10.1016/j.jaerosci.2004.12.001

[11] D.B.Kittelson, W.F.Watts, J.P.Johnso, "On-road and laboratory evaluation of combustion aerosols-Part1: Summary of diesel engine results“, Journal of Aerosol Science, vol. 37, issue 8, p.p. 913-930, 2006.

[12] J. Schneider, N. Hock, S. Weimer, S. Borrmann, U. Kirchner. R. Vogt, V. Scheer, "Nucleation Particles in Diesel Exhaust: Composition Inferred from In Situ Mass Spectrometric Analysis ", Environmental Science and Technology, vol. 39(16) p.p. 6153-6161.

[13] T. RÖnkkÖ, A. Virtanen, J.Kannosto, J. Keskinen, M. Lappi, L. Pirjola, "Nucleation Mode Particles with a Nonvolatile Core in the Exhaust of a Heavy Duty Diesel Vehicle ", Environ. Sci. Technol, vol. 41(18, p.p. 63846389, 2007.

[14] C. Rodriguez-Navarro, E. Sebastian, "Role of particulate matter from vehicle exhaust on porous building stones (limestone) sulfation“, Science of The Total Environment, vol. 187, Issue 2, p.p. 79-91, 1996.

[15] David B.Kittelson, "Engines and nanoparticles: a review“, Journal of Aerosol Science, vol.29, Issues 5-6, p.p. 575$588,1998$.

[16] Causes of formation of toxic components in the exhaust gas of the internal combustion engine. URL: https://studbooks.net/982146/ekologiya/prichiny_obrazovaniya_toksichnyh_komponentov_v_og_dvs (accessed June 21, 2019). 